\title{
On the Keller limit and generalization
}

Yue $\mathrm{Hu}^{1 *}$ and Cristinel Mortici ${ }^{2}$

"Correspondence: huu3y6@163.com

'School of Mathematics and Information Science, Henan

Polytechnic University, Jiaozuo, Henan 454000, China

Full list of author information is

available at the end of the article

\section{Abstract}

Let $c$ be any real number and let

$$
u_{n}(c)=(n+1)\left(1+\frac{1}{n+c}\right)^{n+c}-n\left(1+\frac{1}{n+c-1}\right)^{n+c-1}-e
$$

In this note, we establish an integral expression of $u_{n}(c)$, which provides a direct proof of Theorem 1 in (Mortici and Jang in Filomat 7:1535-1539, 2015).

MSC: $35 \mathrm{~B} 05 ; 35 \mathrm{~B} 10$

Keywords: Keller's limit; constant e; integral expression

\section{Introduction motivation}

The limit

$$
\lim _{n \rightarrow \infty}\left(\frac{(n+1)^{n+1}}{n^{n}}-\frac{n^{n}}{(n-1)^{n-1}}\right)=e
$$

is well known in the literature as the Keller's limit, see [2]. Such a limit is very useful in many mathematical contexts and contributes as a tool for establishing some interesting inequalities [3-6].

In the recent paper [1], Mortici et al. have constructed a new proof of the limit and have discovered the following new results which generalize the Keller limit.

Theorem 1 Let $c$ be any real number and let

$$
u_{n}(c)=(n+1)\left(1+\frac{1}{n+c}\right)^{n+c}-n\left(1+\frac{1}{n+c-1}\right)^{n+c-1}-e
$$

Then

$$
\begin{aligned}
& \lim _{n \rightarrow \infty} u_{n}(c)=0, \\
& \lim _{n \rightarrow \infty} n^{2} u_{n}(c)=\frac{e}{24}(1-12 c), \\
& \lim _{n \rightarrow \infty} n^{3} u_{n}\left(\frac{1}{12}\right)=\frac{5 e}{144} .
\end{aligned}
$$

(c) $2016 \mathrm{Hu}$ and Mortici. This article is distributed under the terms of the Creative Commons Attribution 4.0 International License (http://creativecommons.org/licenses/by/4.0/), which permits unrestricted use, distribution, and reproduction in any medium, provided you give appropriate credit to the original author(s) and the source, provide a link to the Creative Commons license, and indicate if changes were made. 
The proof of Theorem 1 given in [1] is based on the following double inequality for every $x$ in $0<x \leq 1$ :

$$
a(x)<(1+x)^{1 / x}<b(x)
$$

where

$$
a(x)=e-\frac{e}{2 x}+\frac{11 e x^{2}}{24}-\frac{21 e x^{3}}{48}+\frac{2,447 e x^{4}}{5,760}-\frac{959 e x^{5}}{2,304}
$$

and

$$
b(x)=a(x)+\frac{959 e x^{5}}{2,304} .
$$

But, this proof has a major objection, namely, for the reader it is very difficult to observe the behavior of $u_{n}(c)$ as $n \rightarrow \infty$.

In this note, we will establish an integral expression of $u_{n}(c)$, which tells us that Theorem 1 is a natural result.

\section{Main results}

To establish an integral expression of $u_{n}(c)$, we first recall the following result we obtained in [7].

Theorem 2 Let $h(s)=\frac{\sin (\pi s)}{\pi} s^{s}(1-s)^{1-s}, 0 \leq s \leq 1$. Then for every $x>0$, we have

$$
\left(1+\frac{1}{x}\right)^{x}=e\left(1-\sum_{j=1}^{\infty} \frac{b_{j}}{(1+x)^{j}}\right)
$$

where

$$
\begin{aligned}
& b_{1}=\frac{1}{2}, \\
& b_{j}=\frac{1}{e} \int_{0}^{1} s^{j-2} h(s) d s \quad(j=2,3, \ldots) .
\end{aligned}
$$

In $[8]$ (see also $[9,10])$ Yang has proved that $b_{2}=\frac{1}{24}, b_{3}=\frac{1}{48}$.

Hence

$$
\begin{aligned}
& \int_{0}^{1} h(s) d s=\frac{e}{24}, \\
& \int_{0}^{1} \operatorname{sh}(s) d s=\frac{e}{48} .
\end{aligned}
$$

Now, we establish an integral expression of $u_{n}(c)$. Equation (2.1) implies the following results:

$$
\left(1+\frac{1}{n+c}\right)^{n+c}=e\left(1-\sum_{j=1}^{\infty} \frac{b_{j}}{(1+n+c)^{j}}\right),
$$




$$
\left(1+\frac{1}{n+c-1}\right)^{n+c-1}=e\left(1-\sum_{j=1}^{\infty} \frac{b_{j}}{(n+c)^{j}}\right)
$$

Hence by (2.2), (2.3), (2.6), and (2.7), we have

$$
\begin{aligned}
u_{n}(c)= & \frac{e}{2}\left(\frac{n}{n+c}-\frac{n+1}{1+n+c}\right)+\int_{0}^{1} h(s) \sum_{j=2}^{\infty} \frac{n s^{j-2}}{(n+c)^{j}} d s \\
& -\int_{0}^{1} h(s) \sum_{j=2}^{\infty} \frac{(n+1) s^{j-2}}{(1+n+c)^{j}} d s .
\end{aligned}
$$

Note that

$$
\begin{aligned}
& \frac{e}{2}=\int_{0}^{1} 12 h(s) d s \\
& \sum_{j=2}^{\infty} \frac{n s^{j-2}}{(n+c)^{j}}=\frac{1}{(n+c)(n+c-s)}, \\
& \sum_{j=2}^{\infty} \frac{(n+1) s^{j-2}}{(1+n+c)^{j}}=\frac{1}{(1+n+c)(1+n+c-s)} .
\end{aligned}
$$

Therefore, from (2.8)-(2.11), we obtain the desired result:

$$
u_{n}(c)=\int_{0}^{1} h(s) \frac{(1-12 c) n^{2}+\left(1-12 c+24 c s-24 c^{2}\right) n+K}{(n+c)(1+n+c)(n+c-s)(1+n+c-s)} d s
$$

where

$$
K=s^{2}-(1+2 c) s+c+c^{2} .
$$

From (2.12), we get immediately

$$
\begin{aligned}
\lim _{n \rightarrow \infty} u_{n}(c)=0 & \\
\lim _{n \rightarrow \infty} n^{2} u_{n}(c) & =\int_{0}^{1}(1-12 c) h(s) d s \\
& =\frac{e}{24}(1-12 c), \\
\lim _{n \rightarrow \infty} n^{3} u_{n}\left(\frac{1}{12}\right) & =\int_{0}^{1}\left(2 s-\frac{1}{6}\right) h(s) d s \\
& =\frac{e}{24}-\frac{1}{6} \times \frac{e}{24} \\
& =\frac{5 e}{144} .
\end{aligned}
$$

\section{Conclusions}

We have established an integral expression of $u_{n}(c)$, which provides a direct proof of Theorem 1 in [1] and tell us that Theorem 1 is a natural result. We believe that the expression will lead to a significant contribution toward the study of Keller's limit. 
Competing interests

The authors declare that there is no conflict of interests regarding the publication of this article.

\section{Authors' contributions}

The authors completed the paper together. They also read and approved the final manuscript.

\section{Author details}

'School of Mathematics and Information Science, Henan Polytechnic University, Jiaozuo, Henan 454000, China.

${ }^{2}$ Department of Mathematics, Valahia University of Târgovişte, Bd. Unirii 18, Târgovişte, 130082, Romania.

\section{Acknowledgements}

The work was supported by the National Natural Science Foundation of China, No. 11471103.

Received: 9 January 2016 Accepted: 12 March 2016 Published online: 25 March 2016

\section{References}

1. Mortici, C, Jang, X: Estimates of $(1+1 / x)^{x}$ involved in Carleman's inequality and Keller's limit. Filomat 7, 1535-1539 (2015)

2. Sandor, J, Debnath, L: On certain inequalities involving the constant $e$ and their applications. J. Math. Anal. Appl. 249(2), 569-582 (2000)

3. Polya, G, Szego, G: Problems and Theorems in Analysis, vol. I. Springer, New York (1972)

4. Hardy, GH, Littlewood, JE, Polya, G: Inequalities. Cambridge University Press, London (1952)

5. Mortici, C, Hu, Y: On some convergences to the constant e and improvements of Carleman's inequality. Carpath. J. Math. 31, 249-254 (2015)

6. Mortici, C, Hu, Y: On an infinite series for $(1+1 / x)^{x}$. arXiv:1406.7814 [math.CA]

7. $\mathrm{Hu}, \mathrm{Y}$, Mortici, C: On the coefficients of an expansion of $\left(1+\frac{1}{x}\right)^{x}$ related to Carleman's inequality. arXiv:1401.2236 [math.CA]

8. Yang, X: Approximations for constant e and their applications. J. Math. Anal. Appl. 262,651-659 (2001)

9. Gyllenberg, M, Yan, P: On a conjecture by Yang. J. Math. Anal. Appl. 264, 687-690 (2001)

10. Chen, $\mathrm{H}$ : On an infinite series for $\left(1+\frac{1}{x}\right)^{x}$ and its application. Int. J. Math. Math. Sci. 11, 675-680 (2002)

\section{Submit your manuscript to a SpringerOpen ${ }^{\circ}$ journal and benefit from:}

- Convenient online submission

Rigorous peer review

- Immediate publication on acceptance

- Open access: articles freely available online

- High visibility within the field

- Retaining the copyright to your article 